\title{
Cerebral Palsy: A Lifelong Challenge Asks for Early Intervention
}

\author{
Christos P. Panteliadis ${ }^{1, *}$, Christian Hagel ${ }^{2}$, Dieter Karch $^{3}$ and Karl Heinemann ${ }^{3}$ \\ ${ }^{1}$ Paediatric, Division of Paediatric Neurology and Developmental Medicine, Aristotle University of Thessaloniki, \\ Greece \\ ${ }^{2}$ Institute of Neuropathology, University Medical Center Hamburg-Eppendorf, Germany \\ ${ }^{3}$ Clinic of Paediatric Neurology and Social Paediatrics, Children Centre Maulbronn, Germany
}

\begin{abstract}
One of the oldest and probably well-known examples of cerebral palsy is the mummy of the Pharaoh Siptah about 1196-1190 B.C., and a letter from Hippocrates (460-390 B.C.). Cerebral palsy (CP) is one of the most common congenital or acquired neurological impairments in paediatric patients, and refers to a group of children with motor disability and related functional defects. The visible core of CP is characterized by abnormal coordination of movements and/or muscle tone which manifest very early in the development. Resulting from pre- or perinatal brain damage $\mathrm{CP}$ is not a progressive condition per se. However, without systematic medical and physiotherapeutic support the dystonia leads to muscle contractions and to deterioration of the handicap. Here we review the three general spastic manifestations of CP hemiplegia, diplegia and tetraplegia, describe the diagnostic procedures and delineate a time schedule for an early intervention.
\end{abstract}

Keywords: Cerebral palsy, early diagnosis, early intervention.

\section{INTRODUCTION}

One of the oldest and probably well-known examples of cerebral palsy is the mummy of the Pharaoh Siptah. He ruled for 6 years towards the end of the 19th dynasty (1196-1190 B.C), dying at the age of 20 (the average age for CP patients). This case of cerebral palsy is well documented in medical literature thanks to published photographs of the Pharaoh's marked foot deformity [1, 2]. In ancient Greece, Hippocrates (Greek: Hippokrátes) was known as the Father of Medicine. In his work "Of the Eight-Month Foetus", Hippocrates (460-390 B.C.) discusses the association of prematurity, congenital infection and prenatal stress in relation to the pathogenesis of brain damage. He refers to children with "intrauterine disease" as having increased morbidity and mortality He was the first to mention that "women who gave birth to lame, blind or children with any other deficit, had foetal distress during the 8th month of pregnancy" and also that "pregnant women who have fever or lost too much weight, without any obvious cause, gave birth to their child with difficulty and dangerously, or they would abort dangerously" [3-6] (see Table 1).

Concrete examples and definitions of cerebral palsy, however, did not emerge until the early $19^{\text {th }}$ century with observations by William John Little; thus, Little was the first personality to intensely engage in cerebral palsy $[7,8]$. Towards the end of the 19th century, two further personalities

*Address correspondence to this author at the Paediatric, Division of Paediatric Neurology and Developmental Medicine, Aristotle University of Thessaloniki, Greece, Avdella 10, 55131 Thessaloniki, Greece;

Tel: 00302310446482; E-mail: cpanteliadis@hotmail.gr emerged, adding to the historical hallmarks of cerebral palsy: William Osler and Sigmund Freud [9, 10]. The significant developments that have followed since then are all due to the contributions of these three personalities in the field of cerebral palsy.

Cerebral palsy is one of the most common congenital or acquired neurological impairments in children (CP, "pare-

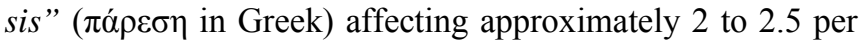
1000 life births. The condition is recognised in early childhood and persists throughout life. $\mathrm{CP}$ is a term (an umbrella term) that has been applied to children predominantly suffering from motor dysfunction and related service requirements. " $C P$ describes a group of permanent disorders of the development and posture, causing activity limitation that are attributed to non-progressive disturbances that occurred in the developing fetal or infant brain. The motor disorders of cerebral palsy are often accompanied by disturbances of sensation, perception, cognition, communication, and behaviour, by epilepsy, and by secondary musculoskeletal problems" [11].

Modern diagnostic techniques like ultrasound and magnetic resonance imaging complement the diagnostic spectrum and allow to identifying central nervous system damage reliably in early life. Any patient who is found to suffer from a certain disorder is stigmatized by the diagnosis but also gains back some of his capacity to act. Medical professionals and parents are enabled to face up to the problem, to plan therapy and to develop future perspectives for the infant. This general consideration and the need to minimize secondary changes developing in long standing $\mathrm{CP}$ call for an early diagnosis and treatment [12]. 
Table 1. Chronological history and terminology of cerebral palsy.

\begin{tabular}{|c|c|c|}
\hline Period & Name & Comments \\
\hline 1196-1190 B.C & Egyptian monuments and mummies & $\begin{array}{l}\text { Pharaoh Siptah with deformity probably due to congeni- } \\
\text { tal abnormality rather than to poliomyelitis }\end{array}$ \\
\hline $5^{\text {th }}-4^{\text {th }}$ Century B.C & Hippokrates, Ploutarchos & $\begin{array}{l}\text { Role of prematurity, congenital infections and prenatal } \\
\text { stress }\end{array}$ \\
\hline $\begin{array}{l}1820-1830 \\
1830-1831\end{array}$ & $\begin{array}{l}\text { Reil, Cazauviehl, Lejumeau, de Kergaradec } \\
\text { Andrey, Heine, Depeck } \\
\text { Billard, Cruveilhier, Breschet, Lallemand, Rokitansky }\end{array}$ & $\begin{array}{l}\text { Reported "cerebral atrophy" in adult } \\
\text { Reported cerebral atrophy in children }\end{array}$ \\
\hline 1889 & Osler & $\begin{array}{l}\text { First two introduce the term "cerebral palsy" and pro- } \\
\text { vided the first classification of CP }\end{array}$ \\
\hline $1891-1897$ & Freud & $\begin{array}{l}\text { Included prenatal factors in pathogenesis of CP. Provid- } \\
\text { ed the most comprehensive classification for spastic } \\
\text { diplegia }\end{array}$ \\
\hline $1885-1888$ & Mc Nutt, Gower & $\begin{array}{l}\text { Described "birth palsies" and identified "first born" } \\
\text { children as being at risk for CP. }\end{array}$ \\
\hline 2000 & Functional MRI, PET, & Use of MRI, SPECT and PET \\
\hline $2000-2008$ & $\begin{array}{l}\text { Gross Motor Function Classification System (GMFCS), } \\
\text { Bimanual Fine Motor Function (BFMF), Manual Ability } \\
\text { Classification System (MACS) }\end{array}$ & \\
\hline
\end{tabular}

\section{CLINICAL EVALUATION}

The abnormal motor status (movement and posture) is the visible core of the clinical picture of $\mathrm{CP}$, and is characterized by abnormal coordination of movements and/or muscle tone. The motor impairments of $\mathrm{CP}$ manifest very early in the development of a child. The infants are usually between 12-18 months of age when the delay in psychomotor development is observed and may be even younger in severe cases. Activity limitations are a consequence of the motor disorders. Therefore, disorders of movement and posture that are not associated with limitations in motor activity are not considered part of the CP group [11].

The brain of the child with CP is in consistent neurodevelopmental conflict, as the impaired cerebral function hampers the physiologic course of growth and maturation of the motor system as well as perception and cognition. Therefore, treatment should stimulate the development of the child in its entirety which also means to coach the whole family (family centred approach). However, due to the evolving character of symptoms, an early diagnosis and the differential diagnosis of CP may be difficult and in some cases impossible during the first 12 to 24 months of life.

According to Nelson and Ellenberg [13] there is only a weak prognostic significance of a formal neonatal examination referring to $\mathrm{CP}$. The first symptoms are disturbances of muscle tone (either hypo- or hypertonic), persistence of primitive reflexes (e.g. Moro, ATNR), abnormal postures and movements and delayed motor milestones. However, these 
symptoms are not CP-specific. They may be observed in all disturbances of brain development including pure mental retardation and autism, but also as a transient phenomenon of unknown aetiology with a benign outcome.

As further pathological signs, Prechtl and colleagues [14] proved the quality of spontaneous general movements (GMs) - particularly during the third month of corrected (postmenstrual) age - to be a reliable and valid tool for distinguishing between infants who are at significant risk of developing neurological deficits and infants who are not [14]. Central to the study were the age-specific "fidgety movements" - small movements of the neck, trunk and limbs in all directions and of variable acceleration [15]. They are the predominant motor pattern in awake infants aged 3 to 5 months [16]. Infants develop normally if such fidgety GMs are present and nor$\mathrm{mal}$, even if their brain ultrasound findings indicate a disposition to neurological deficits in later life. Conversely, if fidgety movements are absent, infants develop neurological deficits even if their ultrasound does not indicate a significant risk [17]. However, although abnormal GMs are indicative for neurological deficits they are not a specific sign for CP $[18,19]$.

More specific symptoms are observed during the third and fourth trimesters of life when a spastic hemiplegic pattern or hypertonic patterns in the arms and legs with scissoring and increased deep tendon reflexes may develop. These signs may already indicate the type of CP. Diplegia, tetraplegia, hemiplegia and the ataxic and dyskinetic forms of $\mathrm{CP}$ correspond to injury in different locations of the brain, involve different cellular elements, and can be assigned to particular times of injury and different causes [12].

\section{DIPLEGIA}

In preterm infants diplegia is the typical picture of $\mathrm{CP}$. Frank periventricular necrosis due to severe perinatal anoxia necessitating resuscitation (accompanied with diffuse whitematter gliosis) or diffuse white-matter-gliosis only, resulting from complications during intensive care phases (or between 25 th -33 th week of the pregnancy) are the neuropathological substrates $[12,20]$. The lesion is located in the border zone between long penetrators from the cortex and long basal penetrators frequently affecting the white matter anterior to the frontal horns, near the lateral corners of the lateral ventricles where the upper part of the pyramidal radiation runs. Intra- or periventricular haemorrhagic infarction damage may increase the extent of the lesion in the immature tissue of the germinal matrix [20].

There is usually a silent period of 6-12 weeks during which the above findings may subside and therefore the diagnosis may elude the clinical examination. However, a careful neurological examination in high-risk infants may reveal some suspicious neurological findings like hypotonia after the $3^{\text {rd }}$ to $4^{\text {th }}$ month (corrected age) of life. The child has poor head control and abnormally easily provoked primitive reflexes, especially the Moro reflex, the automatic walking and tonic neck reflexes. The examination at this stage may reveal a lethargic baby lying in a semi flexed position with little spontaneous movement, especially of the legs [21]. Primitive reflexes may still persist; the asymmetric tonic neck reflex (ATNR), palmar and plantar grasp reflexes are abnormally loose. Initially hypertonia is of the rigid type with the legs extended at the knees and plantar-flexed at the ankles. Later deep tendon reflexes are hyperactive in all extremities and pyramidal signs are easily elicited.

\section{TETRAPLEGIA}

Tetraplegia commonly results from severe global hypoxic-ischemic injury which may occur at different developmental stages. Early in development this may lead to porencephaly, consisting of bilateral defects in the insula and in the gyrus praecentralis and postcentralis. Massive damaging of the immature brain tissue, such as it occurs if both Aa. carotis internae are affected, may lead to hydranencephaly. A hypoxic-ischemic injury of the brain towards the end of gestation or in early infancy may lead to multicystic encephalopathy. The alterations present as multiple bilateral cavities with varying distribution separated from each other through gliotic tissue [12].

In most cases the infant is hypotonic before the appearance of increased muscle tone. Primitive reflexes (Moro, automatic neck reflex) remain longer than normal; there is difficulty in feeding while later scissoring appears as well as flexion posture of the upper limbs. It is common to find hyperextension and opisthotonus in the supine position and flexion in the prone. In severe cases contractures appear as the child matures.

\section{DYSKINESIA}

\section{Imaging Mathod}

During the past decades new methods in brain imaging were developed providing the clinician with detailed pictures of the developmental state and possible lesions of the brain. Ultrasound (pre-and postnatal), computer tomography (CT), magnetic resonance imaging (MRI), functional MRI, transcranial magnetic Stimulation (TMS), MRI spectroscopy and positron emission tomography (PET), diffusiontensorimaging (DTI) among others may be used during pregnancy or in the postnatal period yielding information not only about the anatomy but also on the metabolism, blood supply etc [12]. However, the possibilities to obtain data on the function of the newborn brain are still limited.

Marbled state of the basal ganglia refers to an irregular whitish appearance of the thalamus or striatum due to an abnormal network of thinly myelinated fibres running in an irregular pattern through glial scars. The anomalies are recognisable histologically at about 6 months of age and may be readily seen macroscopically when the fibres in the basal ganglia are fully myelinated. In addition to the basal ganglia the claustrum, red nucleus and subthalamic nucleus may be affected, whereas the substantia nigra, amygdala and mamillary bodies are usually spared. Marbled state may result from 
prolonged delivery at term. Clinically changes in muscle tone may relate to posture and emotional state. Hypertonia is of the rigid type (lead pipe) in contrast to the spastic types. Corresponding to the neuroanatomical development typical extrapyramidal movements are rare during the neonatal period. They start several months later and have a slow progression. The pattern of abnormal muscle tone and movement in dyskinetic CP also progressively develops between 5 and 10 months of age and the full picture may not be completed before the age of 2 years (Foley 1992). There is a delay in the loss of primitive reflexes. Involuntary movements and abnormal posture are obvious in the second half of the 1st year of life with the clinical features completed by the 2 nd year. After the 2 nd year of life, the clinical presentation includes involuntary movements of athetosis, chorea and dystonia, which are more obvious in the supine position. Facial movements are affected the most [22].

\section{HEMIPLEGIA}

The typical picture of congenital hemiplegia results from a territorial infarction due to thrombembolic occlusion of an artery. The lesions are mainly seen in mature infants [23]. Complete occlusion of a cerebral artery results in unilateral focal necrosis of the brain tissue most frequently located in the territory of the left middle cerebral artery which may be explained by haemodynamic differences due to a patent ductus arteriosus and by the shorter distance between heart and left carotid artery in comparison to the right side. Occlusion of the vessel leads to hemiplegia of the trunk, arm and head. In contrast, infarction in the territory of the anterior cerebral artery results in a paresis of the leg [12]. Proximal occlusion of the middle cerebral may also involve the anterior cerebral artery resulting in a complete hemiplegia. In preterm infants the hemiplegia often originates from periventricular haemorrhagic infarction (and periventricular leucomalacia).

\section{ATAXIA}

Ataxia may also be a feature of CP. A decreased cerebellar volume was found in severely premature newborns especially after prolonged artificial respiration [24]. Patients with ataxic $\mathrm{CP}$ have fewer neurological complications when compared to other types of CP. Ataxic CP presents with hypotonia during early infancy and delay of the gross motor functions. After the 6th month, the lack of balance is obvious. These children are clumsy/unskillful and unable to perform precise and quick movements. This type of $\mathrm{CP}$ is characterised by significant heterogeneity both for its aetiology and for the clinical appearance. However, diagnosis can be misled. The clinical findings can be ensured by ultrasound and other imaging and laboratory methods.

\section{THERAPY}

The decision on a therapeutical intervention is guided by several considerations [25]:

1. neural plasticity and critical periods of development,
2. extent of brain injury and signs predicting prognosis,

3. familial environment, and

4. concepts and goals of intervention.

Ad 1) Due to the plasticity of the developing nervous system it may adjust to an injury depending on the time and location of the impact. The plasticity is based on several factors:

- growing axons may take alternative routes to their targets,

- each hemisphere initially develops cortico-spinal projections to the ipsi- and contra-lateral extremity,

- a large fraction of neurons go into apoptosis between gestational week 32 and the early postnatal period suggesting that the surplus of neurons may adopt other functions if connected to proper targets [26],

- growing dendrites and remodelling dendritic fields, which are regulated by activity [27], in adult rats a sustained neocortical neurogenesis has been documented after neonatal hypoxic/ischaemic injury, which could contribute to the ability to recover from injury [28],

- Rha et al. [29] treated rats with unilateral cerebral injury inflicted at postnatal day 7 after a time interval of 4 weeks in different environments and found a significantly higher generation of new neurons in the subventricular zone in animals that lived in an enriched environment. Kolb et al. [30] demonstrated that a reduced growth of dendrites of pyramidal neurons after focal cortical lesioning in newborn rats was reversible if the animals were housed comfortably and received tactile stimuli.

- In children with uni- or bilateral cerebral lesions who were examined by means of TMS between the 3rd and 24th month of life a progressive reduction of synaptic connectivity was found due to lack of cortico-spinal activity [31]. These findings were confirmed in cats. Uni-lateral inactivity of the cortico-spinal tract resulted in aberrant cortico-spinal terminations and decreased numbers of interneurons as well as M1 motor map defects. However, early electric stimulation of the injured extremities and training restored corticospinal tract connections and the M1 motor map [32, 33].

The animal data thus suggest critical periods for the motor development which would correspond to an age of several months up to one year in humans.

Hence, severe damage will regularly result in early and severe symptoms whereas small or focal injuries that occurred early in gestation are better adjusted for and will become clinically apparent only later.

Ad 2) Location and extent of the CNS lesion primarily defines the development of the child and the efficacy of the 
therapy. Severe injuries cause deficits which are often only partially compensated for by therapy. However, this does not exclude the possibility of substantial improvement by activation of remaining functions like improvement of vision in children with neonatal damage in the occipital lobes.

Repeated investigations of the brain in the first postnatal weeks and months by ultrasound and MRI generally render the more valuable information concerning prognosis $[24,34$, 35 ] than performing just one investigation at a fixed date [36].

Van Wezel-Meijler et al. [37] conducted a study on very premature or low birth weight neonates evaluating the prognostic value of repeated ultrasound investigations. The ultrasound findings were complemented by MRI at the calculated date of term. In cases where a periventricular echo density was observed in at least one investigation a white matter lesion was seen in MRI and in children with peri- or intraventricular haemorrhage (Volpe grade I-III) this was always confirmed by MRI indicating an unfavourable prognosis. Normal ultrasound findings always indicated a favourable course even if the MRI showed conspicuous findings. The study thus confirmed in part older investigations [38].

Numerous follow-up investigation of severely premature children confirm a high risk for developmental retardation in CP including global cognitive impairment or developmental disorders of scholastic skills which may only be noticed in school [39-41]. Hence the concept of a therapy only addressing motor skills seems to be outdated.

$\mathrm{CP}$ in mature newborns is relatively rarely caused by hypoxia-ischemia. Prognosis in these cases is deduced from the clinical course assessed according to the modified classification of Sarnat and Sarnat [42]. The brain injury usually is observed in conjunction with other pre- and perinatal complications like intracranial haemorrhage, seizures or connatal disorders. Early clinical symptoms are similar to those described above; later tetraparesis may develop which commonly is associated with cognitive and emotional retardation.

Ad 3) The significance of the family for the development of the child is increasingly acknowledged. Family centred therapeutical concepts are now available like COPCA (Coping with and caring for infants with special needs) which includes informing the parents about the child's disorder and coaching them to involve the child in a broad spectrum of activities [43]. Further, the parents themselves need support with their fears and worries [44] and should be involved in the management of the child in an emancipated way $[45,46]$. 2011.

Ad 4) In the past different physiotherapeutic techniques and concepts have been developed to diminish the neurologic symptoms like extensive passive cross-pattern exercises of the extremities, similar to the movement pattern of amphibians for "neurological organisation" [47-49] or intensive passive training by inducing the coordination complexes "reflex creeping" and "reflex rolling" to create the basis ("start level") for a normal motor development $[50,51]$ and inhibition of abnormal movement patterns response reflexes and facilitation of more or less normal patterns of posture and purposeful movements [52, 53]. More recently multidisciplinary treatment strategies have been recommended which do not any longer solely focus on the movement disorder. The Bobath concept has also been changed accordingly. Reflecting current neurobiological insights into the mode of function of the therapeutical measures the regimens include a family centred approach [54], and comply with many elements used in the preventive exploitation of high-risk infants. The therapists train parents and carers in ways to assist their child to achieve best performance [55]. In general, advanced motivation and inspiration of the intrinsic activity of the child is the focus of therapy so that an increased sensorimotor experiences can be gathered and functional improvement achieved. The patient becomes the active part in the setting, with increase of age pathological movements are accepted. Catchwords for therapy are: Practice makes perfect; Use it or lose it; Fire together - wire together; No changes without reward.

Priority is given to the accomplishment of everyday tasks, largely independent of the quality of the movement sequences as long as this does not worsen pre-existing contractions. However, although the early developmental intervention programs in preterm infants improved cognitive function at the infant age they showed no long term effect when assessed at the school age. In systematic reviews performed by Orton et al. [56] and Blauw-Hospers et al. [57] there was little evidence of an effect on motor functions in the short-, medium- or long-term. Thus in children in whom $\mathrm{CP}$ or a severe psychomotor retardation develops the aims of intervention have to be individually and constantly adjusted over years according to the individual (dis)abilities. The efficacy of a concept that is not solely focused on motor development has previously been shown in a controlled trial with spastic diplegic children, between 12 and 19 months of age [58].

A systematic literature analysis documented a relatively good efficacy for constraint induced therapy, hip surveillance, botulinum toxin, selective dorsal rhizotomy, contextfocused therapy, goal-directed training, fitness training and purpose-built home training programmes given that the indication is individually adapted [59].

In the last decade children have been treated with hemiplegic $\mathrm{CP}$ intervention programs to overcome the "learned non-use" in adult hemiplegia, which are strongly child- and impairment orientated. The efficacy of the constraintinduced movement therapy (CIMT) and the hand-arm intensive bimanual therapy (HABIT) depends on the cooperation of the child which can be expected not before an age of about 4 years. The efficacy depends also on the size of the cerebral lesion and the extent of ipsi-lateral projections which can negatively influence the result $[60,61]$. Although the effects of CIMT were evaluated in several therapeutic trials an optimal protocol for therapy could not be established and a long lasting improvement of quality of life for the children was not proven until now [62].

Cognitive development is much less at risk in congenital hemiplegia or after perinatal stroke than in spastic diplegia 
or tetraplegia [63]. Occupational therapy and physiotherapy are indicated in motor symptoms differing between right and left side.

\section{TIME SCHEDULE FOR AND EARLY INTERVER- TION}

\section{Prevention}

The risk factors for $\mathrm{CP}$ could be identified by a metaanalysis in children born mature. However, there is only a small chance to avoid the risk factors [64]. In cases of perinatal illnesses such as fits, respiratory distress syndromes or hypoglycemia timely state-of-the-art clinical management helps to prevent irreversible brain injury. Preventing birth before the $34^{\text {th }}$ week of gestation is one of the most important concerns since these children have a risk of about 50 $\%$ to develop CP Medical care should aim at.

- reduction of multiple births after in-vitro fertilisation,

- early recognition and treatment of prenatal intraamniotic infections or sepsis and possible sequelae [65-67].

- in case of habitual abortion or preterm delivery examination of the fetus and the mother to identify individual causes followed by adequate pre-conceptual counselling of the mother, and

- critical analysis of the data gained by fetal electronic monitoring $[68,69]$.

Most of the very premature children are treated in hospital and require long term intensive care and artificial respiration. In order to prevent further complications like haemorrhagic stroke any stress should be avoided and gentle physical contact should be offered [70]. The parents need to be involved in the management of the child as early as possible. Previous studies have shown that this may shorten the stay in hospital $[71,72]$. However, whether this regimen also influences psychomotor development has not been shown conclusively. According to Guzetta et al. [73] massage of the baby diminishes stress and fosters development. Both, premature children and children at high risk should be seen frequently by a paediatrician after discharge from the hospital to take preventive measures as early as possible $[74,75]$.

\section{Therapy}

At the age of 3 months high-risk infants with a birth weight of less than $1250 \mathrm{~g}$ who suffered from severe preand/or perinatal complications (which may lead to CP) and who showed neurological abnormalities at term as well as alterations in CNS imaging should be neurologically reevaluated and their motor development should be assessed according to criteria of Prechtl or Hadders-Algra respectively $[14,25]$. Children with suspicious findings should be seen again after 4 weeks. If functional abnormalities are confirmed interventions are initiated as described above. This proceeding, which differs from former concepts, is indicated because confirmed abnormal neurological findings point to serious deficits in psycho-motor development and a risk of

CP. The treatment has to be adjusted to any peculiarities that may appear later like disturbed motor function of the mouth, cognitive retardation etc. making use of the different forms of therapy like speech or occupational therapy and physiotherapy respectively. Later more specific interventions are indicated like HABIT, CIMT or treadmill training.

The first thing should be to inform parents and /or caregivers carefully about the possibility that the baby has a developmental retardation and that there is a risk that the child can develop a form of CP. According to Hadders-Algra [25] it is important to coach parents and inform them about all facts that could influence the developmental process. Children have to explore their ADL-surrounding and make experience, favourable seems to be an ADL-setting how and where problems have to be solved and children have to adapt in their performance.

Despite great efforts in research many open questions remain in CP $[12,14,16]$. The main goal should be to continue identifying the divergent aetiologies and to prevent $\mathrm{CP}$ in order to reduce the percentage of children with brain damage. Herskind et al. [76] argue that infants offered early intervention in future clinical studies must be identified carefully, and that the intervention should be focused on infants showing early signs of CP to determine an effect of treatment.

In summary, the most important points concerning in early treatment are

- to start general supportive activities within the first year of life to achieve the best possible benefit for the child,

- $\quad$ to assure a loving and stimulating atmosphere during the training and to perform the exercises with the family members or the next caregivers,

- to provide not only technical guidance but also psychological and psychosocial support to the caregivers,

- to communicate not only active but also passive interventions such as in feeding, bedding and head control (handling) to the caregivers in order to help to avoid contractures or hip dislocation,

- $\quad$ to adjust the treatment setting individually and include frequent repetitions and positive feedback to promote the essential intrinsic motivation and self-activity,

- to promote sensorimotor (and mental) development analogous to that in normal children; it may be necessary to divide the training in very small development steps,

- to implement specific and targeted therapies or even CIMT at an appropriate age. For example, training the hand-mouth movement is a goal-oriented activity which is possibly achieved only with the support of the postural control, and

- to address associated symptoms separately such as deficits in oral motor skills or eating disorders. 


\section{CONFLICT OF INTEREST}

The authors confirm that this article content has no conflict of interest.

\section{ACKNOWLEDGEMENTS}

Declared none.

\section{REFERENCES}

[1] Ikram S, Dodson A. The mummy in ancient Egypt. Thames and London: Hudson 1998.

[2] Harris J, Wende E. An X-ray atlas of the royal mummies. Chicago and London. University of Chicago Press 1980.

[3] Lipourlis D. The suffix in presocratic philosophy and in the Hippocratic corpus. Thessalonik, Aristotle University, 1968 (in Greek).

[4] Lipourlis D. The suffix in presocratic philosophy and in the Hippocratic corpus. Thessaloniki, Aristotle University, 1968. (In Greek).

[5] Nestle W. Hippocratica. Hermes 1938; 73: 1-38.

[6] Panteliadis C, Panteliadis P, Vassiliady F. Hallmarks in the history of cerebral palsy: From antiquity to mid- $20^{\text {th }}$ century. Brain $\&$ Dev 2013; 35: 285-292.

[7] Accardo P. William John Little and Cerebral Palsy in the Nineteenth Century. J Hist Med Allied Sci 1989; 44: 56-71.

[8] Little W. On the nature and course treatment of deformities of human frame. Being a course of lectures delivered at the Royal Orthopedic Hospital in 1843 and 1844. London: Longman, Brown, Green and Longmanns 1853.

[9] Osler W. The cerebral palsies of children: a clinical study from the infirmary for nervous diseases. Philadelphia: Blakiston P 1889.

[10] Freud S. Die infantile Cerebrallähmung. In: Nothnagel H, ed. Nothnagel's Specielle Pathologie und Therapie. Wien: Holder 1897.

[11] Bax M, Goldstein M, Rosenbaum P, et al. Proposed definition and classification of cerebral palsy. Dev Med Child Neurol 2005; 47 : 571-76.

[12] Panteliadis CP. Cerebral palsy- A multidisciplinary approach. Dustri Verlag Dr. Karl Feistle, München-Orlando 2011.

[13] Nelson KB, Ellenberg JH. Neonatal signs as predictors of cerebral palsy. Pediatrics 1979; 64: 225-32.

[14] Prechtl HFR. State of the art of the new functional assessment of the young nervous system. An early predictor of cerebral palsy. Early Hum Dev 1997; 50: 1-11.

[15] Hopkins B, Prechtl HFR. A qualitative approach to the development of movements during early infancy. In: Prechtl HFR, Ed. Continuity of neural functions from prenatal to postnatal life. Clin Dev Med 1984; 94: 179-97.

[16] Einspieler C, Prechtl HFR, Bos AF. Prechtl's method on the qualitative assessment of general movements in preterm, term and young infants. Clin Dev Med 2004; 167: 1-91.

[17] Einspieler C, Kerr AM, Prechtl HFR. Is the early development of girls with Rett disorder really normal? Pediatr Res 2005; 57: 696700 .

[18] Groen SE, Blecourt ACE, Postema K, Hadders-Algra M. General movements in early infancy predict neuromotor development at 9 to 12 years of age. Dev Med Child Neurol 2005; 47:731-8.

[19] Darsaklis V, Snider LM, Majnemer A, Mazer B. Predictive validity of Prechtl's method on the qualitative assessment of general movements: a systematic review of evidence. Dev Med Child Neurol 2011; 53: 896-906.

[20] Folkerth RD. Neuropathologic substrate of cerebral palsy. J Child Neurology 2005; 20: 940-9.

[21] Wichers M, Hilberink S, Roebroeck ME, et al. Motor impairments and activity limitations in children with spastic cerebral palsy: a Dutch population-based study. J Rehabil Med 2009; 41: 367-74.

[22] Yokochi K, Shimabukuro S, Kodama M, et al. Motor function of infants with athetoid cerebral palsy. Dev Med Child Neurol 1993; 35: 909-16.

[23] Nelson KB, Lynch JK. Stroke in newborn infants. Lancet Neurol 2004; 3: 150-8.
[24] Limperopoulos C, Soul JS, Gauvreau K, et al. Late gestation cerebellar growth is rapid and impeded by premature birth. Pediatrics 2005; 115: 688-95.

[25] Hadders-Algra M. Challenges and limitations in early intervention. Dev Med Child Neurol 2011; 53(Suppl 4): 52-5.

[26] Rabinowicz T, de Courten-Myers GM, Petetot JM, et al. Human cortex development: estimates of neuronal numbers indicate major loss late during gestation. J Neuropathol Exp Neurol 1996; 55: 32028.

[27] Parrish JZ, Emoto K, Kim MD, Jan YN. Mechanisms that regulate establishment, maintenance, and remodeling of dendritic fields. Ann Rev Neuroscience 2007; 30: 399-423.

[28] Yang Z, Covey MV, Bitel CL, et al. Sustained neocortical neurogenesis after neonatal hypoxic/ischemic injury. Ann Neurol 2007; 61: 199-208.

[29] Rha DW, Kang SW, Park YG, et al. Effects of constraint- induced movement therapy on neurogenesis and functional recovery after early hypoxic- ischemic injury in mice. Dev Med Child Neurol 2011; 53: 327-33.

[30] Kolb B, Mychasiuk R, Williams P, Gibb R. Brain plasticity and recovery from early cortical injury. Dev Med Child Neurol. 2011; 53(Suppl 4): 4-8.

[31] Eyre JA, Smith M, Dabydeen L, et al. Is hemiplegic cerebral palsy equivalent to amblyopia of the corticospinal system? Ann Neurol 2007; 62: 493-503.

[32] Martin JH. Chakkrabaty S, Friel KM. Harnessing activitydependent plasticity to repair the damaged corticospinal tract in animal model of cerebral palsy. Dev Med Child Neurol 2011; 53(Suppl 4): 9-13.

[33] Friel K, Chakrabarty S, Kuo H-C, Martin J. Using motor behavior during an early critical period to restore skilled movement after damage to the corticospinal system during development. J Neurosci 2012; 32: 9265-76.

[34] Dyet LE, Kennea N, Counsell SJ, et al. Natural history of brain lesions in extremely preterm infants studied with serial magnetic resonance imaging from birth and neurodevelopmental assessment. Pediatrics 2006; 118: 536-48.

[35] Malik GK, Trivedi R, Gupta RK, et al. Serial quantitative Diffusion Tensor MRI of the term neonates with hypoxic-ischemic encephalopathy. Neuropediatrics 2006; 37: 337-43.

[36] Spittle AJ, Cheong J, Doyle LW, et al. Neonatal white matter abnormality predicts childhood motor impairment in very preterm children. Dev Med Child Neurol 2011; 53:1000-6.

[37] Van Wezel-Meijler G, De Bruione F, Steggerda SJ, et al. Ultrasound detection of white matter injury in very preterm newborn neonates practical implications. Dev Med Child Neurol 2011; 53(Suppl 4): 29-34.

[38] De Vries LS, Groenendaal F, Eken P, et al. Infarcts in the vascular distribution of the middle cerebralartery in preterm and fulltherm infants. Neuropediatrics 1997; 28: 88-96.

[39] Whitaker AH, Feldmann J, Lorenz JM, et al. Motor and cognitive outcomes in nondisabled low-birth-weight adolescents. Early Determinants. Arch Pediatr Adolesc Med 2006; 160: 1040-6.

[40] Saigal S, Stoskopf B, Boyle, et al. Comparison of current health, functional limitations, and health care use of young adults who were born with extremely low birth weight. Pediatrics 2007; 119: e562-73.

[41] Volpe JJ. Brain injury in premature infants a complex amalgam of destructive and developmental disturbances. Lancet Neurol 2009; 8: 110-28.

[42] Sarnat HB, Sarnat MS. Neonatal encephalopathy following fetal distress. Arch Neurol 1976; 33: 696-705.

[43] Hielkema T, Blauw-Hospers CH, Dirks T, et al. Does physiotherapeutic intervention affect motor outcome in high-risk infants? An approach combining a randomized controlled trial and process evaluation. Dev Med Child Neurol 2011; 53: e8-15.

[44] Romeo DM, Cioni M, diStefano A, et al. Quality of life in parents of children with cerebral palsy: is it influenced by the child's behaviour? Neuropediatrics 2010; 41: 121-6.

[45] Darrah J, Law MC, Pollock N, et al. Context therapy: a new intervention approach for children with cerebral palsy. Dev Med Child Neurol 2011; 53: 615-20.

[46] Rosenbaum P. Family and quality of life: key elements in intervention in children with cerebral palsy. Dev Med Child Neurol 2011; 53(Suppl 4): 68-70. 
[47] Fay T. The neurophysical aspects of therapy in cerebral palsy. Archiv Phys Med 1948; 29: 327-4.

[48] Fay T. Neuromuscular reflex therapy for spastic disorders. J Fla Med Assoc 1958; 44: 1234-40.

[49] Doman RJ, Spitz EB, Zucman E, et al. Children with severe brain injuries. Neurological organisation in terms or mobility. JAMA 1960; 174: 257-62.

[50] Vojta V. Early diagnosis of a spastic infantile syndrome. Beitr Orthop Traumatol 1965; 12: 543-5.

[51] Vojta V. The basic elements of treatments according to Vojta. In: Scrutton D, Ed. Management of the motor disorders of the children with cerebral palsy. Oxford: Blackwell Scientific 1984.

[52] Bobath B. The very early treatment of cerebral palsy. Dev Med Child Neurol 1967; 9: 373-90.

[53] Bobath K, Bobath B. Management of the motor disorders of childrens with cerebral palsy. London: Mc Keith Press 1984.

[54] Karch D, Heinemann KJ, Blank R. Physiotherapeutic and occupational treatment of children with cerebral palsy. In: Panteliadis CP, Ed. Cerebral Palsy. A multidisciplinary approach, Dustri Verlag Dr. Karl Feistle, München-Orlando 2011; pp. 141-164.

[55] Maystone M. Physiotherapy management in cerebral palsy: an update on treatment approachs. In: Scrutton D, Damiano D, Maystone M. Eds. Management of the motor disorders of children with cerebral palsy. Clinics in Development Machine No. 161; Mc Keith Press, London 2004.

[56] Orton J, Spittle A, Doyle L, et al. Do early intervention programmes improve cognitive and motor outcomes for preterm infants after discharge? A systematic review. Dev Med Child Neurol 2009; 51: 851-9.

[57] Blauw-Hospers CH, de Graaf-Peters VB, Dirks T, et al. Does early intervention in infants at high risk for a developmental motor disorder improve motor and cognitive development? Neurosci Biobehav Rev 2007; 31: 1201-12.

[58] Palmer FB, Shapiro BK, Wachtel RC, et al. The effects of physical therapy on cerebral palsy. A controlled trial in infants with spastic diplegia. N Engl J Med 1988; 318: 803-8.

[59] Novak I, McIntyre S, Morgan C, et al. A systematic review of interventions for children with cerebral palsy: state of evidence. Dev Med Child Neurol 2013; 55: 885-910.

[60] Staudt M. Reorganization after pre- and perinatal brain lesions. J Anat 2010; 217: 469-74.

[61] Juenger H, Kuhnke N, Braun C, et al. Two types of exerciseinduced neuroplasticity in congenital hemiparesis: a transcranial magnetic stimulation, functional MRI, and magnetencephalographic study. Dev Med Child Neurol 2013; 55: 941-51.
[62] Eliasson AC, Krumhilde-Sundholm L, Gordon AM, et al. Guidelines for future research in constraint-induced movement therapy for children with unilateral cerebral palsy: an expert consensus. Dev Med Child Neurol 2014; 56: 125-137.

[63] Ballanthyne O, Brain Spilkin AM, Hesselink J, Trauner DA. Plasticity in the developing brain: intellectual, language and academic functions in children with ischaemic perinatal stroke. Brain 2008; 131: 2975-85.

[64] McIntyre S, Taitz D, Keogh J, et al. A systematic review of risk factors for cerebral palsy in children born at term developed countries. Dev Med Child Neurol 2013; 55: 499-508.

[65] Bashiri, A, Burstein E, Mazor M. Cerebral palsy and fetal inflammatory response syndrome: a review. J Perinatal Med 2006; 34: 512.

[66] Fahey JO. Clinical management of intra-amniotic infection and chorioamnionitis: A review of the literature. J Midwifery Womens Health 2008; 53: 227-35.

[67] Romero R, Gotsch F, Pineles B, Kusanovic JP. Inflammation in pregnancy: its roles in reproductive physiology, obstetrical complications, and fetal injury. Nutrition Rev 2007; 65(12 Pt. 2): S194202.

[68] Nelson KB. Can we prevent cerebral palsy? New Engl J 2003; 349: 1765-9.

[69] Nelson KB, Chang T. Is cerebral palsy preventable? Curr Opin Neurol 2008; 21: 129-35.

[70] Anderson GC (1991) Current knowledge about skin-to-skin (kangaroo) care for preterm infants. J Perinatol 1991; 11: 216-26.

[71] Als H, Duffy FH, McAnulty GB, et al. Early experience alters brain function and structure. Pediatrics 2004; 113: $846-57$.

[72] McAnulty G, Duffy FH, Butler S, Parad R. Individualized developmental care for a large sample of very preterm infants: health, neurobehaviour and neurophysiology. Acta Paediatrica 2009; 98: 1920-26.

[73] Guzetta A, DÁcunto M, Carotenuto M, et al. The effects of preterm infant massage on brain electrical activity. Dev Med Child Neurol 2011; 53 (Suppl.4): 46-51.

[74] Achenbach TM, Phares V, Howell CT, Rauh VA, Nurcombe B. Seven-year outcome of the Vermont intervention program for low birth weight infants. Child Dev 1990; 61: 1672-81

[75] Hadders-Algra M. General movements: a window for early identification of children at high risk developmental disorders. J Pediatr 2004; 145 (Suppl 2): 12-8.

[76] Herskind A, Greisen G, Nielsen JB. Early identification and intervention in cerebral palsy. Dev Med Child Neurol 2015; 57(1): 2936. 